\title{
Microencapsulation of Ascorbic Acid with Tripalmitin by Using Dry Coating Method
}

\author{
Yoshinari Taguchi1 ${ }^{1}$, Hidetoshi Tanabe ${ }^{1}$, Kiyomi Fuchigami2 ${ }^{2}$ Masato Tanaka ${ }^{*}$ \\ ${ }^{1}$ Graduate School of Science and Technology, Niigata University, Niigata, Japan \\ ${ }^{2}$ Department of Research \& Development, Shofu Inc., Kyoto, Japan \\ Email: ${ }^{*}$ tanaka@eng.niigata-u.ac.jp
}

Received 7 January 2015; accepted 26 January 2015; published 30 January 2015

Copyright (C) 2015 by authors and Scientific Research Publishing Inc.

This work is licensed under the Creative Commons Attribution International License (CC BY).

http://creativecommons.org/licenses/by/4.0/

c) (i) Open Access

\begin{abstract}
It was tried to microencapsulate the ascorbic acid powder as a redox initiator with tripalmitin by use of the dry coating method. In the experiment, the feed ratio of the amount of tripalmitin to that of ascorbic acid, the coating time and the concentration of ethyl alcohol of pulverizing solvent were changed stepwise. The characteristics of microcapsules such as the content of core material, the yield, the water proof degree, the microencapsulation efficiency and the mean diameter were estimated. The yield, the microencapsulation efficiency and the water proof degree gradually increased with the feed ratio, the coating time and the concentration of pulverizing solvent. The microcapsules showed the thermal responsibility and induced polymerization of methyl methacrylate monomer.
\end{abstract}

\section{Keywords}

Ascorbic Acid, Tripalmitin Microcapsules, Dry Coating, Redox Initiator, Thermal Responsibility

\section{Introduction}

Microcapsules with the many functions have been prepared and applied to the various fields such as drugs, textiles, information recording materials, paintings, cosmetics, food materials, adhesives, medicine, agriculture and so on [1] [2]. The purposes of microencapsulation are to protect the core material from environment, to release the core material according to occasion demands, to handle the gaseous and the liquid core materials as the solid particles and to modify the surface of core material [2]. Moreover, we can give the microcapsules the various functions by how to select the physicochemical properties of the core and the shell materials and how to combine these materials. For examples, there are the combinations of the hydrophilic core materials with the hydro-

"Corresponding author.

How to cite this paper: Taguchi, Y., Tanabe, H., Fuchigami, K. and Tanaka, M. (2015) Microencapsulation of Ascorbic Acid with Tripalmitin by Using Dry Coating Method. Materials Sciences and Applications, 6, 130-139.

http://dx.doi.org/10.4236/msa.2015.62016 
phobic and/or the hydrophilic shell materials and the combinations of the inorganic core materials with the organic and/or the inorganic shell materials. Also, we can select the shell materials with the various physicochemical properties such as magnetism, electric conductivity, thermal conductivity, chemical resistance, biodegradability and so on [3]-[10].

Ascorbic acid is well known as a redox initiator for polymerization of styrene and methyl methacrylate. If the redox initiator could be microencapsulated and added into these monomers beforehand, polymerization could be induced by breaking the microcapsules due to appropriate stimuli. In dental treatment using polymerization stated above, it has been strongly desired to microencapsulate powdery ascorbic acid with the hydrophobic material. Namely, if ascorbic acid as a redox initiator for polymerization could be microencapsulated with the hydrophobic and chemical resistance materials, the microcapsules could be added into monomer such as styrene and methyl methacrylate beforehand and polymerization should be induced by breaking microcapsules due to heating. As a result, it may be expected that dental treatment has to be extremely improved.

In general, it is well known that the preparation method by using the water phase is not suitable to microencapsulation of water soluble core material [11]-[15]. For example, as the water soluble core materials dissolve in the water phase during the microencapsulation process, the content of core materials may be decreased. Accordingly, it is desirable that the preparation method without the water phase can be applied for microencapsulation of the water soluble materials and the hydrophilic materials. So, it is necessary to develop the method without water for preparing the microcapsules containing the water soluble materials or the hydrophilic materials.

In this study, it is tried to microencapsulate powdery ascorbic acid with tripalmitin as the hydrophobic thermal responsible shell material by using the dry coating method, in which the core and the shell materials are mixed in the mill pot together with pulverizing solvent and the surface of core material is coated with the shell material.

The purposes of this study are to establish the preparation method of microcapsules containing the water soluble ascorbic acid, to investigate how the operational conditions such as the added amount of shell material, the concentration of ethyl alcohol of pulverizing solvent and the coating time affect the characteristics of microcapsules and to apply the microcapsules to polymerization of methyl methacrylate.

\section{Experimental}

\subsection{Materials}

Water soluble core material was L- $(+)$-ascorbic acid (LAA) with the mean diameter of $20 \mu \mathrm{m}$ (Wako Pure Chemical Industries, Ltd.). Tripalmitin (TP) with the melting point of $80^{\circ} \mathrm{C}$ was used as the hydrophobic shell material, which was purchased from Kanto Chemical Co., Inc. Ethyl alcohol (EtOH) (Kanto Chemical Co., Inc.) was used as the pulverizing solvent for the shell material. Methyl methacrylate monomer (Kanto Chemical Co., Inc.) was used to investigate whether the microcapsules could induce polymerization or not.

\subsection{Preparation of Microcapsules}

Figure 1 and Figure 2 show the schematic diagram of experimental apparatus and the flow chart for preparing the microcapsules, respectively. The unmicroencapsulated active materials are easily deactivated by oxygen or humidity in environment. If the active materials could be microencapsulated by the materials with the barrier ability to oxygen or humidity, the activity of microencapsulated materials should be kept for long time. In microencapsulation of the core materials deactivated easily by oxygen or humidity, it is necessary to develop the microencapsulation method without air and humidity. Taking these things into consideration, we have adopted the dry coating method which is performed under nitrogen atmosphere using only the pulverizing solvent.

First, in order to make sure of the shell formation, LAA and TP were premixed for ten min at the revolution speed of $60 \mathrm{rpm}$ in the semi mill pot as shown in Figure 1(a) by adding the given volume of EtOH. In the semi mill pot, ten nylon balls with the diameter of $7 \mathrm{~mm}$ were added. Then, the three semi mill pots containing the mixture of LAA and TP were set in the mill pot to increase the production amount of microcapsules as shown in Figure 1(b) and mixed for the given time at the revolution speed of $60 \mathrm{rpm}$. Microencapsulation may progress in turn partial solution of TP with EtOH, adhesion of TP and film formation on the surface of LAA particles. In the preparation method of microcapsules presented here, the concentration of EtOH $\left(\mathrm{C}_{\mathrm{E}}\right.$ : wt\% to TP), the added amount of TP to change the feed ratio $(\mathrm{R})$ of TP to LAA, the size of LAA and the coating time were mainly changed. Table 1 shows the experimental conditions adopted in this study. 


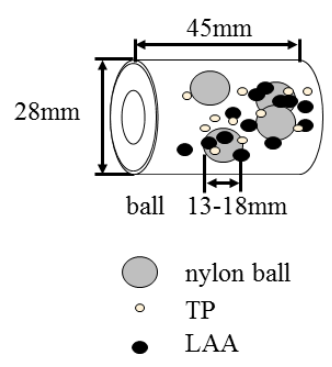

(a)

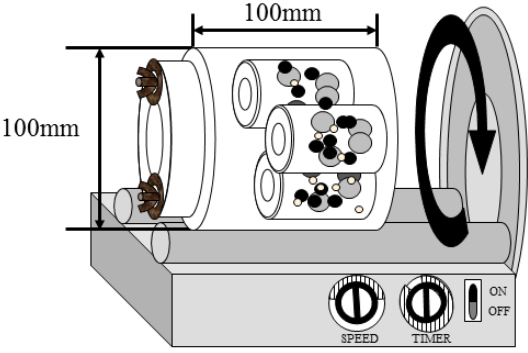

(b)

Figure 1. Schematic diagram of experimental apparatus. (a) Semi mill pot; (b) Mill pot.

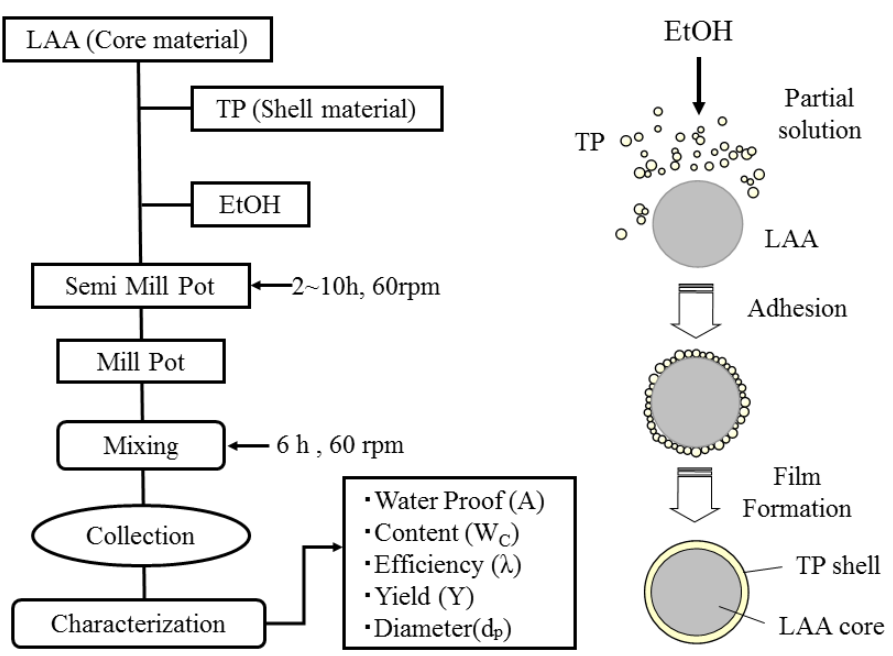

Figure 2. Flow chart for preparing microcapsules.

Table 1. Experimental conditions.

\begin{tabular}{cc}
\hline L-(+)-Ascorbic acid (LAA) & $2.5 \mathrm{~g}$ \\
Diameter of LAA & $\mathrm{D}_{\mathrm{A}}=20,115,220,349[\mu \mathrm{m}]$ \\
Tripalmitin ( $\left.\mathrm{D}_{\mathrm{S}}=21.5 \mu \mathrm{m}\right)$ & $1.1-3.0 \mathrm{~g}$ \\
Feed ratio of LAA to TP & $\mathrm{R}=7 / 3,6 / 4,5 / 5,4 / 6,3 / 7$ \\
Pulverizing medium & Ten nylon balls $(1.55 \mathrm{~g})$ \\
Premixing time (semi mill pot) & $10 \mathrm{~min}$ \\
Rotational velocity (semi mill pot) & $60 \mathrm{rpm}$ \\
Mixing time (mill pot) & $\mathrm{t}=2,4,6,8,10 \mathrm{~h}$ \\
Rotational velocity (mill pot) & $60 \mathrm{rpm}$ \\
Concentration of EtOH (C $\mathrm{E})$ & $\mathrm{C}_{\mathrm{E}}=0 \mathrm{wt} \%, 1.3 \mathrm{vol} \%, 2.0 \mathrm{vol} \%$ \\
\hline
\end{tabular}

\subsection{Characterization of Microcapsules}

Microcapsules prepared as stated above were characterized about the following things:

\subsubsection{Observation of Microcapsules and LAA}

The surface and morphology of a microcapsule and the LAA particles were observed by scanning electron microscope (SEM) (VE-9800, Keyence Corp., Osaka, Japan). 


\subsubsection{Mean Diameters of Microcapsules and LAA}

The diameters of microcapsules $\left(\mathrm{d}_{\mathrm{p}}\right)$ and LAA particles $\left(\mathrm{D}_{\mathrm{A}}\right)$ were measured by the sieve classification method.

\subsubsection{Water Proof Degree}

First, LAA of a given weight was dissolved into distilled water of $40 \mathrm{~cm}^{3}$ and then, the concentration of $\mathrm{NaOH}$ to neutralize the LAA aqueous solution was measured by titrating with $0.02 \mathrm{~mol} / \mathrm{L} \mathrm{NaOH}$ aqueous solution. From these results, the correlating curve between the concentration of LAA and that of $\mathrm{NaOH}$ was obtained beforehand. Then, the microcapsules of $0.5 \mathrm{~g}$ were added into distilled water of $40 \mathrm{~cm}^{3}$ to be dispersed for $30 \mathrm{~min}$ by mixing gently with the magnetic stirrer, under which conditions any microcapsules were not broken mechanically. After this operation, the given volume $\left(10 \mathrm{~cm}^{3}\right)$ of aqueous solution, in which the microcapsules were dispersed, was sampled out and then, the concentration of $\mathrm{NaOH}$ to neutralize this solution was measured. By comparing the measured concentration of $\mathrm{NaOH}$ with the correlating curve, the concentration of LAA leaking from the microcapsules was estimated. Moreover, the remaining microcapsules were redispersed in distilled water of $40 \mathrm{~cm}^{3}$ and broken by heating up to $80^{\circ} \mathrm{C}$ to completely dissolve LAA microencapsulated. Thus, the weight of LAA not leaking from the microcapsules was estimated in the same manner as stated above. From these values, the water proof degree (A) was calculated by using the following Equation (1).

$$
\mathrm{A}=\frac{\text { weight of LAA remaining in microcapsules }}{\text { initial weight of LAA microencapsulated }}
$$

\subsubsection{Content, Microencapsulation Efficiency, Yield}

The content $\left(\mathrm{W}_{\mathrm{C}}\right)$ of core material, the microencapsulation efficiency $(\lambda)$, the yield $(\mathrm{Y})$ were calculated by using the following equations from the measured values.

$$
\begin{gathered}
\mathrm{W}_{\mathrm{C}}=\frac{\text { total weight of LAA microencapsulated }}{\text { weight of microcapsules }} \\
\lambda=\frac{\text { total weight of LAA microencapsulated }}{\text { weight of LAA in feed }} \\
\mathrm{Y}=\frac{\text { weight of microcapsules prepared }}{\text { weight of TP and LAA in feed }}
\end{gathered}
$$

\subsubsection{Application of Microcapsules to Polymerization of MMA}

The microcapsules $(0.5 \mathrm{~g})$ were added into the test tube, in which $10 \mathrm{~cm}^{3}$ of MMA monomer dissolving potassium persulfate (KPS) was poured beforehand. It was observed whether polymerization could be induced by heating the test tube at $130^{\circ} \mathrm{C}$ and breaking the microcapsules or not. For comparison, the same experiments as stated just above were conducted by adding only LAA with heating at $50^{\circ} \mathrm{C}$ and by adding the microcapsules with heating at $50^{\circ} \mathrm{C}$, respectively. The microcapsules were not broken at $50^{\circ} \mathrm{C}$.

\section{Results and Discussion}

\subsection{Effect of Diameter Ratio of LAA to TP}

Figure 3 shows the SEM photographs of LAA particles with the different diameters. The mean diameters $\left(\mathrm{D}_{\mathrm{A}}\right)$ of LAA particles are $250 \mu \mathrm{m}$ (a), $200 \mu \mathrm{m}$ (b), $150 \mu \mathrm{m}$ (c), $21.5 \mu \mathrm{m}$ (d), respectively. While, the mean diameter $\left(D_{S}\right)$ of TP particles was $20 \mu \mathrm{m}$. The LAA particles are irregular and wide distribution.

Figure 4 shows the effect of ratio of mean diameters $\left(D_{A}\right)$ of LAA particles to those $\left(D_{S}\right)$ of TP particles on the characteristics of microcapsules where the feed ratio (R) of LAA to TP was 5/5 and the coating time was $6 \mathrm{~h}$. With increasing the values of ratio, namely, the number of TP particles per a LAA particle, the yield (Y), the microencapsulation efficiency $(\lambda)$ and the water resistance degree (A) considerably increased. Here, on supposing that LAA particles are spherical particles, the surface area of LAA particles with the diameters of $250 \mu \mathrm{m}$, $200 \mu \mathrm{m}$ and $150 \mu \mathrm{m}$ become equal to in turn $0.09,0.11,0.14$ times of that of LAA particles with the diameter of $21.5 \mu \mathrm{m}$. Accordingly, the larger the amount of TP per a LAA particle, the denser the TP shell. 


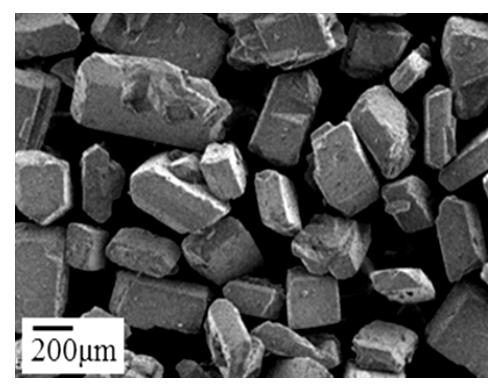

(a)

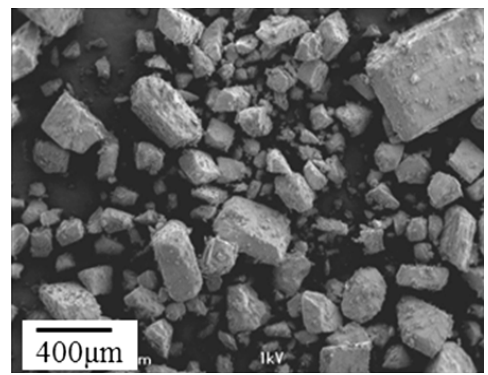

(c)

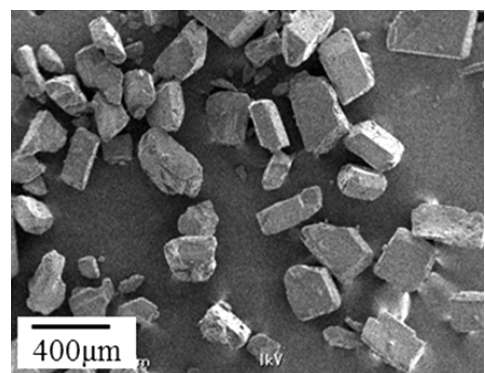

(b)

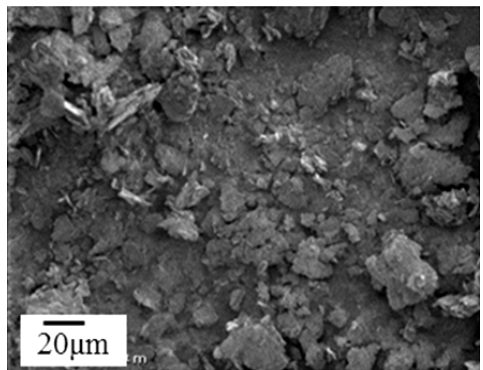

(d)

Figure 3. SEM photographs of LAA particles. (a) $\mathrm{D}_{\mathrm{A}}=250[\mu \mathrm{m}]$; (b) $\mathrm{D}_{\mathrm{A}}=$ $200[\mu \mathrm{m}] ;$ (c) $\mathrm{D}_{\mathrm{A}}=150[\mu \mathrm{m}] ;$ (d) $\mathrm{D}_{\mathrm{A}}=21.5[\mu \mathrm{m}]$.

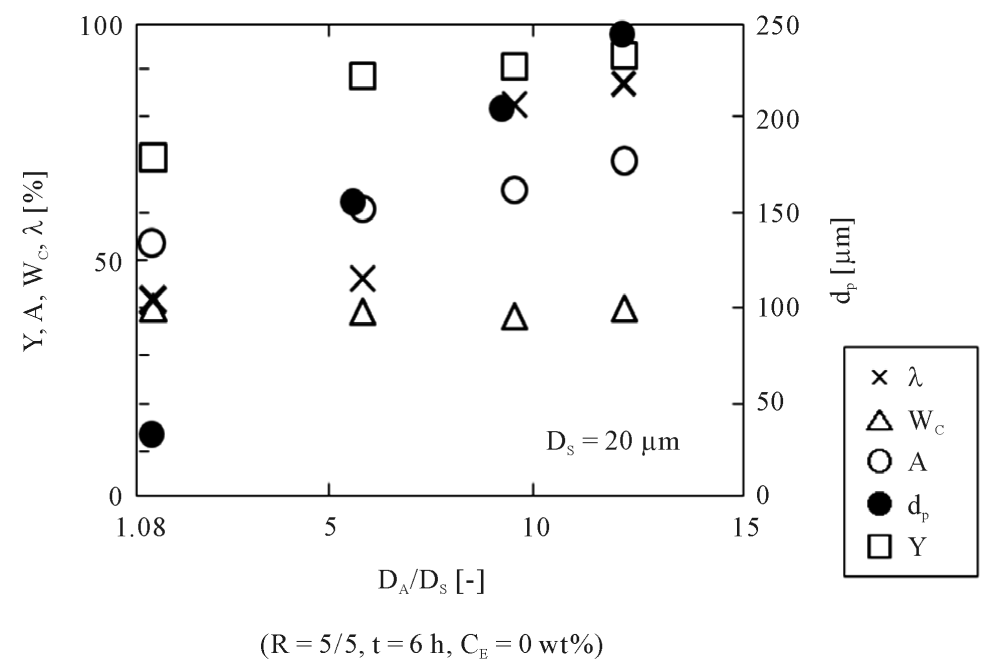

Figure 4. Effect of ratio of diameters of LAA to that of TP.

On the other hand, the content $\left(\mathrm{W}_{\mathrm{C}}\right)$ was kept almost constant $\left(\mathrm{W}_{\mathrm{C}}=0.4\right)$ and close to the calculated content $\left(\mathrm{W}_{\mathrm{C}}=0.42\right)$ based on the feed ratio of LAA and TP. The mean diameters of microcapsules increased according to the diameters of LAA particles.

\subsection{Effect of Coating Time}

Figure 5 shows the SEM photographs of microcapsules taken each at elapsing time where the diameter ratio $\left(D_{A} / D_{S}\right)$ of LAA particles to TP particles was 10.0 and the feed ratio (R) of LAA to TP was 5/5. It was found that the adhesion amount of TA on the LAA particles increased with the coating time and the denser shell was formed.

Figure 6 shows the dependences of the yield $(\mathrm{Y})$, the water proof degree $(\mathrm{A})$, the content $\left(\mathrm{W}_{\mathrm{C}}\right)$ and the microencapsulation efficiency $(\lambda)$ on the coating time. The microencapsulation efficiency $(\lambda)$ rapidly increased 


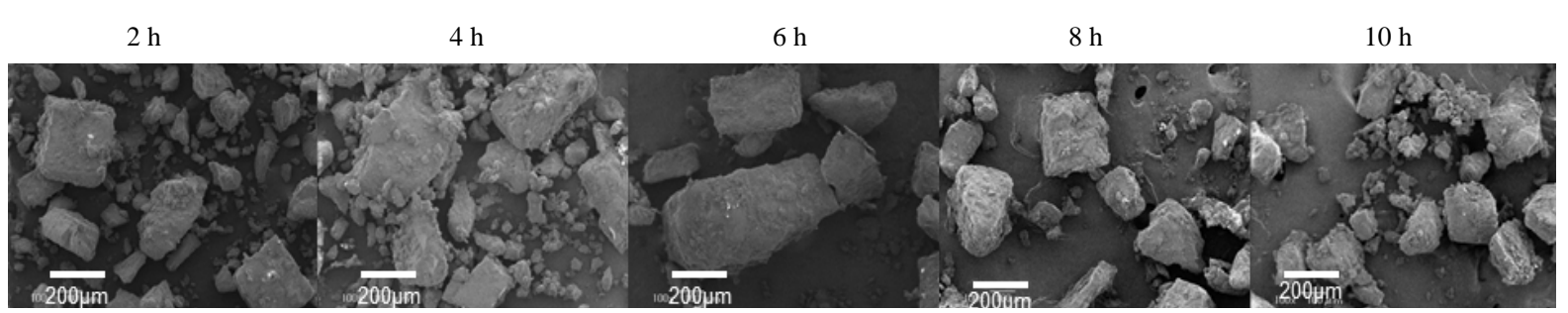

(a)

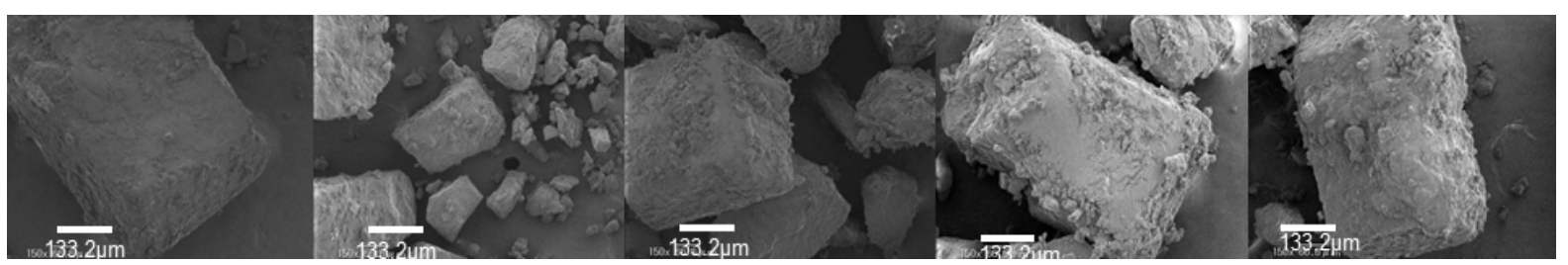

(b)

$\left(D_{A} / D_{S}=10, C_{E}=0, R=5 / 5\right)$

Figure 5. SEM photographs of microcapsules (effect of coating time).

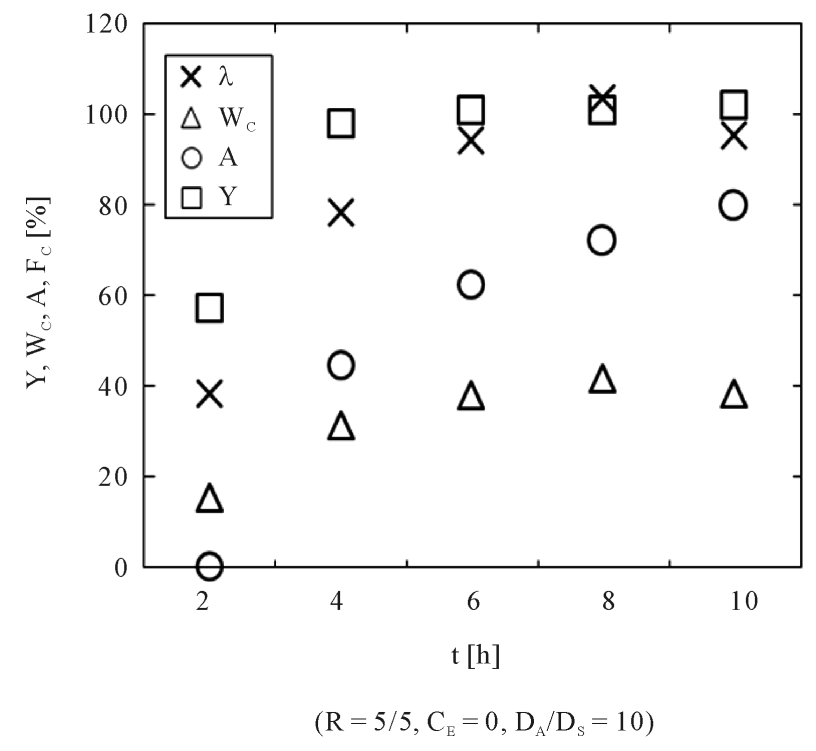

Figure 6. Effect of coating time.

from $40 \%$ to ca. $100 \%$ after $6 \mathrm{~h}$. The water proof degree $(\mathrm{A})$ increased from 0 at $\mathrm{t}=2 \mathrm{~h}$ to $80 \%$ at $\mathrm{t}=10 \mathrm{~h}$. The content $\left(\mathrm{W}_{\mathrm{C}}\right)$ increased from 18 at $\mathrm{t}=2 \mathrm{~h}$ to ca. $40 \%$. The yield $(\mathrm{Y})$ increased from $59 \%$ at $\mathrm{t}=2 \mathrm{~h}$ to $100 \%$ at $\mathrm{t}=$ $4 \mathrm{~h}$.

\subsection{Effect of Concentration of Pulverizing Solvent}

Figure 7 shows the SEM photographs of microcapsules prepared by changing the concentration of pulverizing solvent at $\mathrm{t}=10 \mathrm{~h}$ where the diameter ratio of LAA particles to TP particles was 10.0 and the feed ratio of LAA to TP was 5/5. With increasing the concentration of pulverizing solvent, the adhesion amount of TA increased and the denser shell was formed.

Figure 8 shows the dependence of the yield $(Y)$, water proof degree $(A)$, the content $\left(\mathrm{W}_{\mathrm{C}}\right)$ and the microencapsulation efficiency $(\lambda)$ on the concentration of pulverizing solvent. The yield $(\mathrm{Y})$ reached $100 \%$ at $\mathrm{C}_{\mathrm{E}}=1.3$ vol\%. The content $\left(\mathrm{W}_{\mathrm{C}}\right)$ gradually increased and reached $40 \%$ at $\mathrm{C}_{\mathrm{E}}=1.3 \mathrm{vol} \%$. The water proof degree $(\mathrm{A})$ and the microencapsulation efficiency $(\lambda)$ gradually increased from $79 \%$ at $\mathrm{C}_{\mathrm{E}}=0 \mathrm{wt} \%$ to $90 \%$ at $\mathrm{C}_{\mathrm{E}}=2.0 \mathrm{wt} \%$ and 


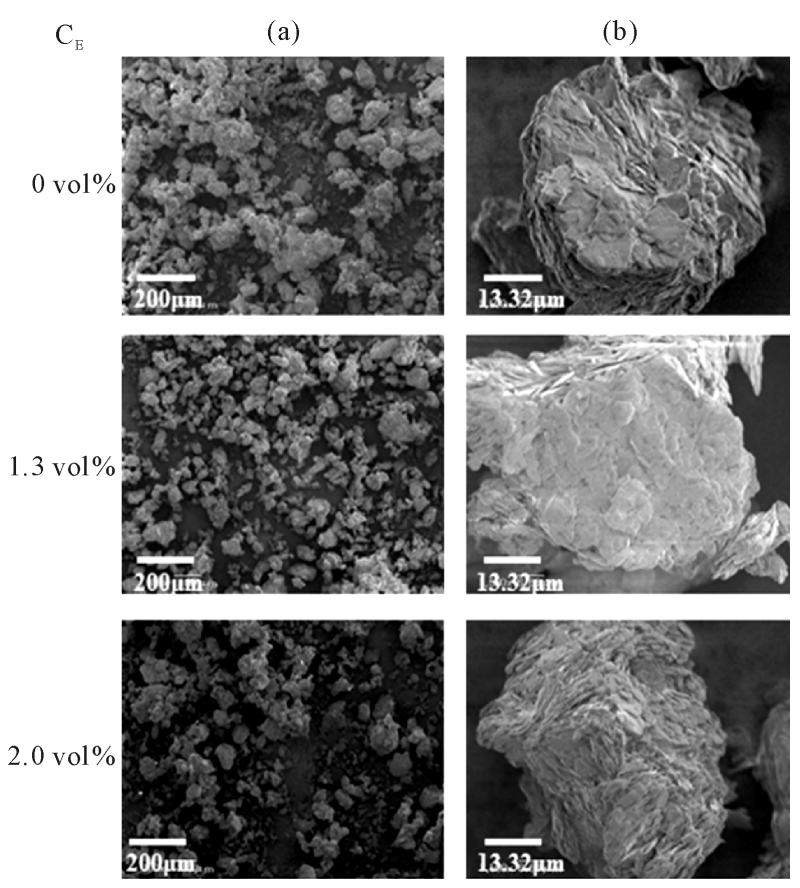

$\left(\mathrm{R}=5 / 5, \mathrm{t}=10 \mathrm{~h}, \mathrm{D}_{\mathrm{A}} / \mathrm{D}_{\mathrm{S}}=10.0\right)$

Figure 7. SEM photographs of microcapsules (effect of concentration of EtOH).

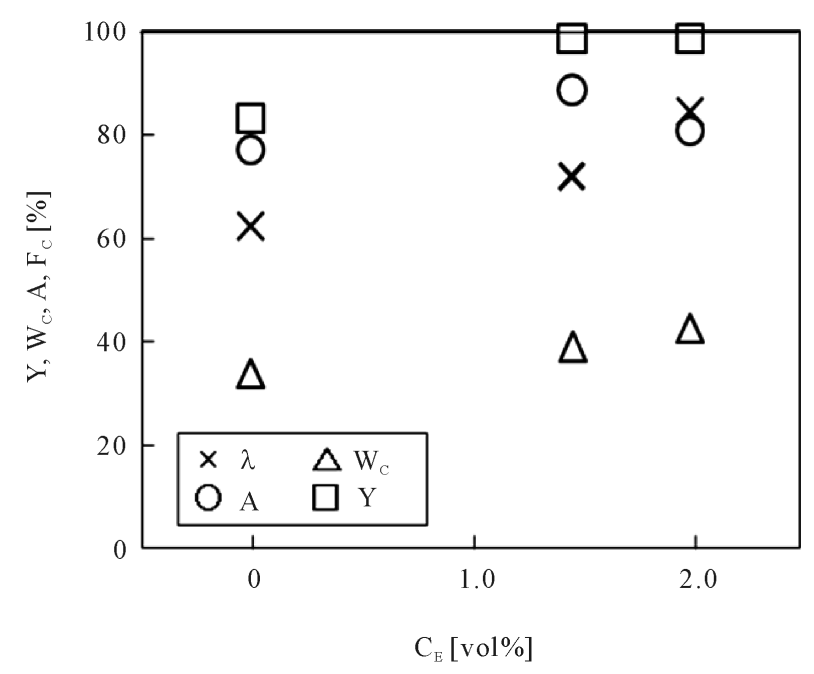

Figure 8. Effect of concentration of EtOH.

from $61 \%$ at $\mathrm{C}_{\mathrm{E}}=0 \mathrm{wt} \%$ to $82 \%$ at $\mathrm{C}_{\mathrm{E}}=2.0 \mathrm{wt} \%$, respectively.

\subsection{Effect of Feed Ratio}

Figure 9 shows the SEM photographs of microcapsules prepared by changing the feed ratio (R) of TP to LAA at $\mathrm{t}=6 \mathrm{~h}, \mathrm{D}_{\mathrm{A}} / \mathrm{D}_{\mathrm{S}}=10$ and $\mathrm{C}_{\mathrm{E}}=1.3 \mathrm{wt} \%$. It was found that the larger the ratio, the denser the shell become.

Figure 10 shows the dependences of the yield $(\mathrm{Y})$, the water proof degree $(\mathrm{A})$, the content $\left(\mathrm{W}_{\mathrm{C}}\right)$, the microencapsulation efficiency $(\lambda)$ on the feed ratio $(\mathrm{R})$. The yield $(\mathrm{Y})$ become $100 \%$ at each feed ratio. The microencapsulation efficiency $(\lambda)$ over $90 \%$ could be obtained at each feed ratio. The content $\left(\mathrm{W}_{\mathrm{C}}\right)$ increased with decrease in the feed ratio because of decrease in the amount of shell material in a microcapsule. 


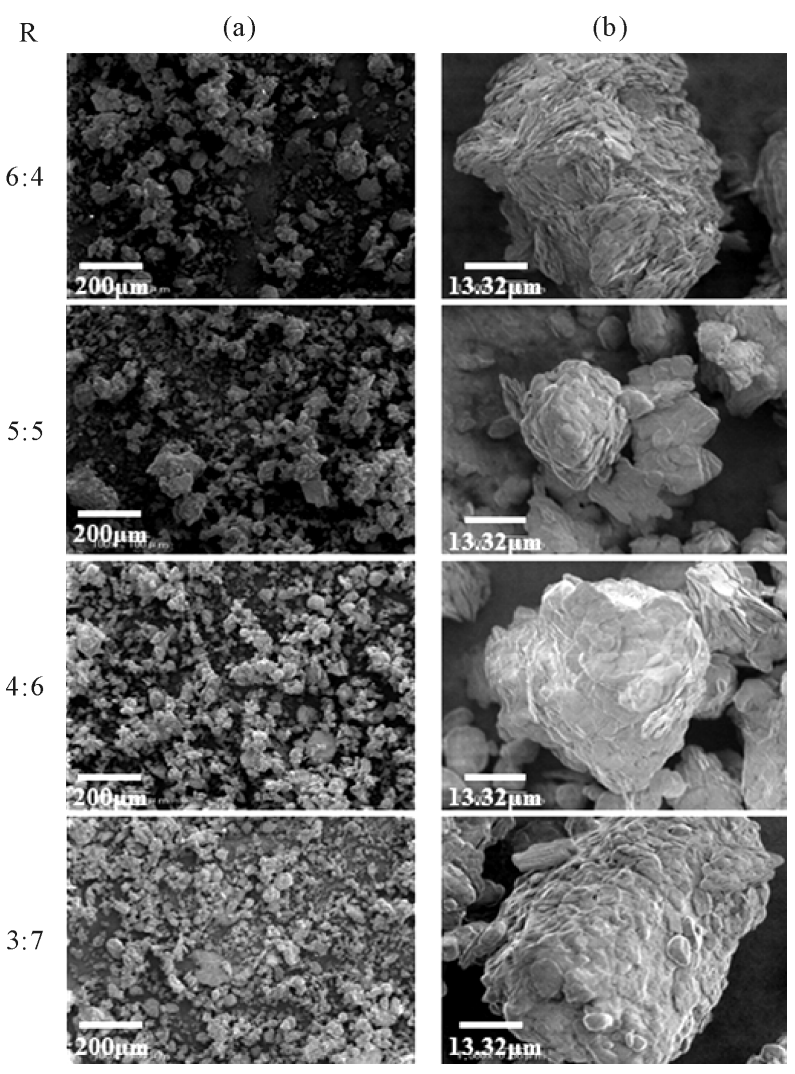

$\left(\mathrm{D}_{\mathrm{A}} / \mathrm{D}_{\mathrm{S}}=10.0, \mathrm{t}=6 \mathrm{~h}, \mathrm{C}_{\mathrm{E}}=1.3 \mathrm{wt} \%\right)$

Figure 9. SEM photographs of microcapsules (effect of feed ratio).

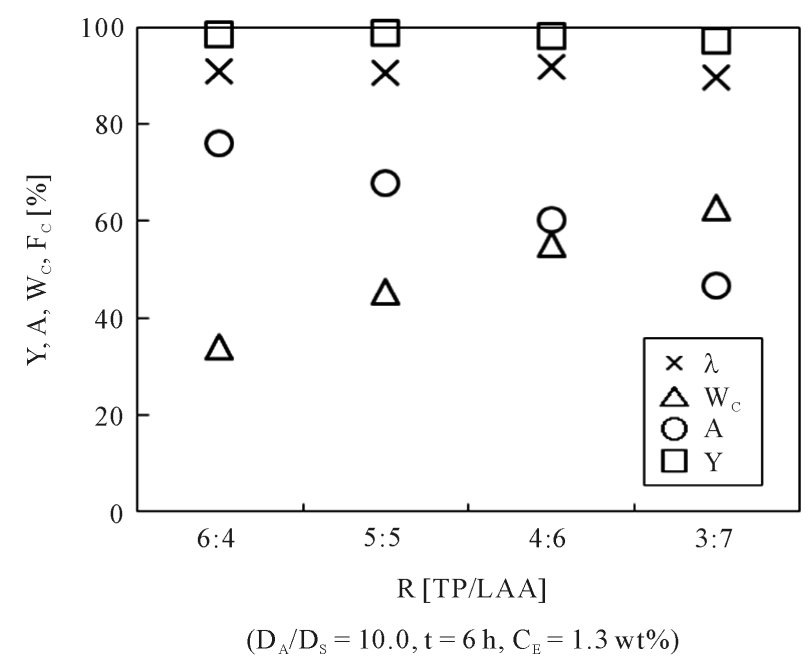

Figure 10. Effect of feed ratio.

\subsection{Application of Microcapsules to Polymerization of Methyl Methacrylate Monomer}

Figure 11 shows the photographs of the polymerization system of MMA monomer, where the microcapsules prepared at $D_{A} / D_{S}=10, C_{E}=1.3 \mathrm{wt} \%, R=5 / 5, t=10 \mathrm{~h}$ were used. The monomer phase was solidified by adding unmicroencapsulated LAA at T $=50^{\circ} \mathrm{C}$ and by breaking the microcapsules due to heating at $130^{\circ} \mathrm{C}$, but was not solidified by adding the microcapsules at $\mathrm{T}=50^{\circ} \mathrm{C}$ because of lower temperature than the melting point of 


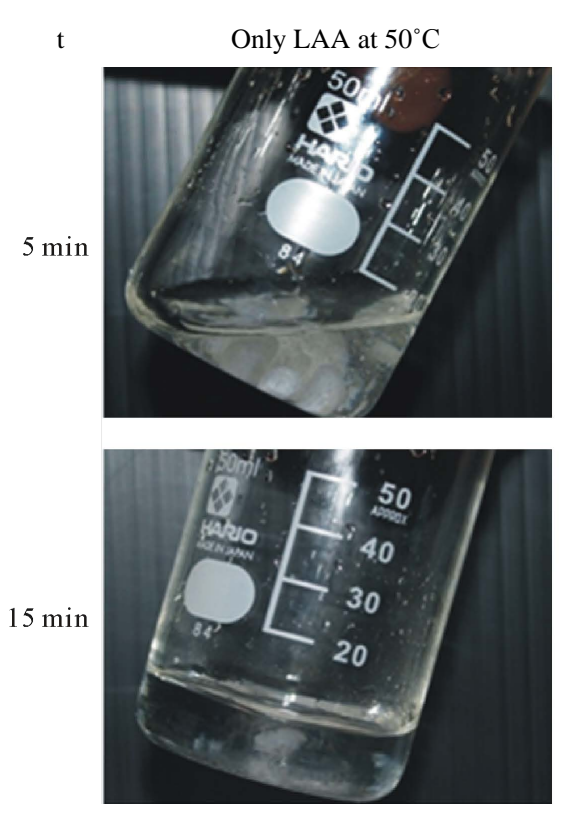

(a)
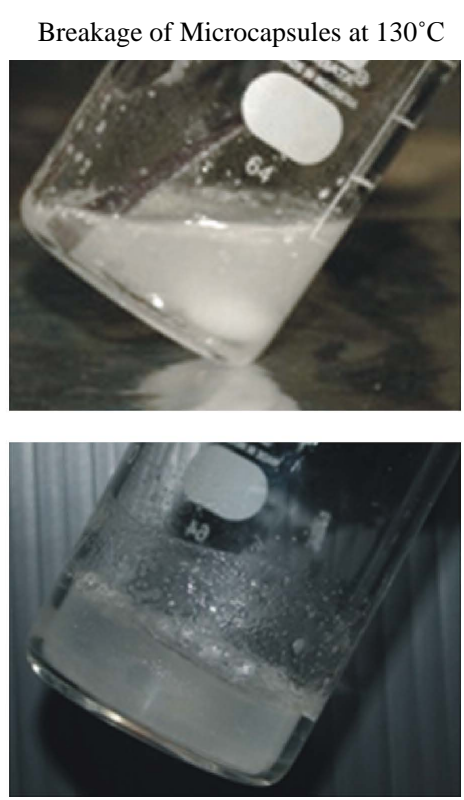

(b)
Microcapsules Without breakage at $50^{\circ} \mathrm{C}$
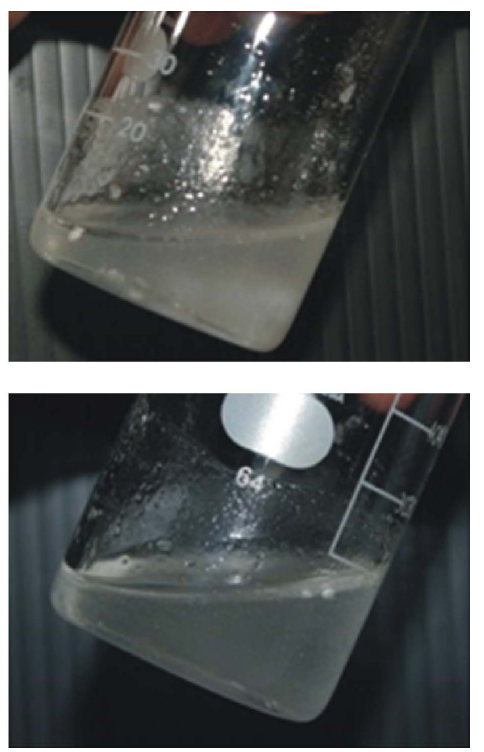

(c)

Figure 11. Application of microcapsules to polymerization.

TP. From this result, it was confirmed that LAA was microencapsulated well and could induce polymerization of MMA monomer.

\section{Conclusions}

It was tried to microencapsulate LAA with TP by using the dry coating method. The fundamental results were obtained as follows.

1) LAA was microencapsulated well with TP.

2) The yield, the content, the water proof degree and the microencapsulation efficiency increased with the coating time.

3) The yield, the microencapsulation efficiency, the content and the water proof degree increased with the mean diameter ratio of LAA particles to TP particles, the feed ratio of LAA to TP and the concentration of pulverizing solvent.

4) It was confirmed that the microcapsules were broken due to heating at $\mathrm{T}=130^{\circ} \mathrm{C}$ and could induce polymerization of methyl methacrylate monomer.

\section{References}

[1] Kondo, T. (1967) Saishin Maikurokapseruka Gijutsu (Microencapsulation Technique). TES, Tokyo.

[2] Tanaka, M. (2008) Key Point of Preparation of Nano/Microcapsules. Techno System Publishing Co. Ltd., Tokyo.

[3] Tanaka, M. and Hayashi, K. (1989) Preparation of Polystyrene Particles Coated with Ferrite Powder by Suspension Polymerization. Kagaku Kogaku Ronbunshu, 15, 1144-1152. http://dx.doi.org/10.1252/kakoronbunshu.15.1144

[4] Tanaka, M. and Hosogai, K. (1990) Suspension Polymerization of Styrene with Circular Loop Reactor. Journal of Applied Polymer Science, 39, 955-966. http://dx.doi.org/10.1002/app.1990.070390414

[5] Tanaka, M., Saito, A., Hosogai, K. and Kimura, I. (1992) Preparation of Fine Polymer Particles Coated Uniformly with Magnetite Powder by Suspension Polymerization. Kagaku Kogaku Ronbunshu, 18, 330-337. http://dx.doi.org/10.1252/kakoronbunshu.18.330

[6] Tanaka, M., Hosogai, K., Yuda, T., Kimura, I. and Saito, N. (1992) Preparation of Composite Particles Composed of Polystyrene and Carbon Silicide by Suspension Polymerization. Journal of the Japan Society of Colour Material, 65, 484-491. http://dx.doi.org/10.4011/shikizai1937.65.484

[7] Kimura, I., Yoshii, H., Saito, N. and Tanaka, M. (1995) Preparation of Composite Particles Constituted of Fine Aluminum Nitride Powder and Polystyrene by Suspension Polymerization. Journal of the Society of Powder Technology 
Japan, 32, 229-236. http://dx.doi.org/10.4164/sptj.32.229

[8] Taguchi, Y., Saito, N., Kimura, I. and Tanaka, M. (1999) Preparation of Fine Composite Particles Composed of Inorganic Solid Powders and Organic Polymers by Utilizing Liquid-Liquid Dispersion. Colloids and Surfaces A: Physiochemical and Engineering Aspects, 153, 401-404. http://dx.doi.org/10.1016/S0927-7757(98)00462-2

[9] Taguchi, Y. and Tanaka, M. (2001) Preparation of Composite Particles Composed of Two Kinds of Solid Powders and Waste Polymer by Semi-Chemical Recycle Method. Journal of Chemical Engineering of Japan, 34, 1177-1181. http://dx.doi.org/10.1252/jcej.34.1177

[10] Taguchi, Y. and Tanaka, M. (2003) Preparation of Composite Particles Made from Solid Powders and Wasted Plastics by Semi Chemical Recycle Method. Journal of Applied Polymer Science, 88, 483-488. http://dx.doi.org/10.1002/app.11920

[11] Kofuji, K., Qian, C.J., Murata, Y. and Kawashima, S. (2005) Preparation of Chitosan Microparticles by Water-inVegetable Oil Emulsion Coalescence Technique. Reactive \& Functional Polymers, 62, 77-83. http://dx.doi.org/10.1016/j.reactfunctpolym.2004.09.002

[12] Chen, M.C., Mi, F.L., Liao, Z.X., Sonaje, K., Chung, M.F., et al. (2013) Recent Advances in Chitosan-Based Nanoparticles for Oral Delivery of Macromolecules. Advanced Drug Delivery Reviews, 65, 865-879. http://dx.doi.org/10.1016/j.addr.2012.10.010

[13] Filho, L.P., Kokol, V. and Voncica, B. (2013) Synthesis and Characterization of Ethyl Cellulose Microcapsules Containing Model Active Ingredients. Macromolecular Symposia, 328, 45-55. http://dx.doi.org/10.1002/masy.201350605

[14] Betz, M. and Kulozik, U. (2011) Microencapsulation of Bioactive Bilberry Anthocyanins by Means of Whey Protein Gels. Procedia Food Science, 1, 2047-2056. http://dx.doi.org/10.1016/j.profoo.2011.10.006

[15] Betz, M., Steiner, B., Schantz, M., Oidtmann, J., Mader, K., Richling, E. and Kulozik, U. (2012) Antioxidant Capacity of Bilberry Extract Microencapsulated in Whey Protein Hydrogels. Food Research International, 47, 51-57. http://dx.doi.org/10.1016/j.foodres.2012.01.010 
Scientific Research Publishing (SCIRP) is one of the largest Open Access journal publishers. It is currently publishing more than 200 open access, online, peer-reviewed journals covering a wide range of academic disciplines. SCIRP serves the worldwide academic communities and contributes to the progress and application of science with its publication.

Other selected journals from SCIRP are listed as below. Submit your manuscript to us via either submit@scirp.org or Online Submission Portal.
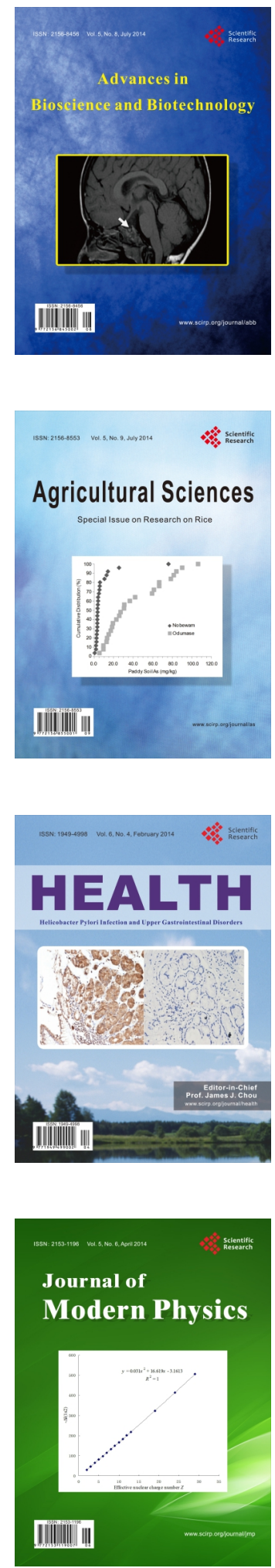
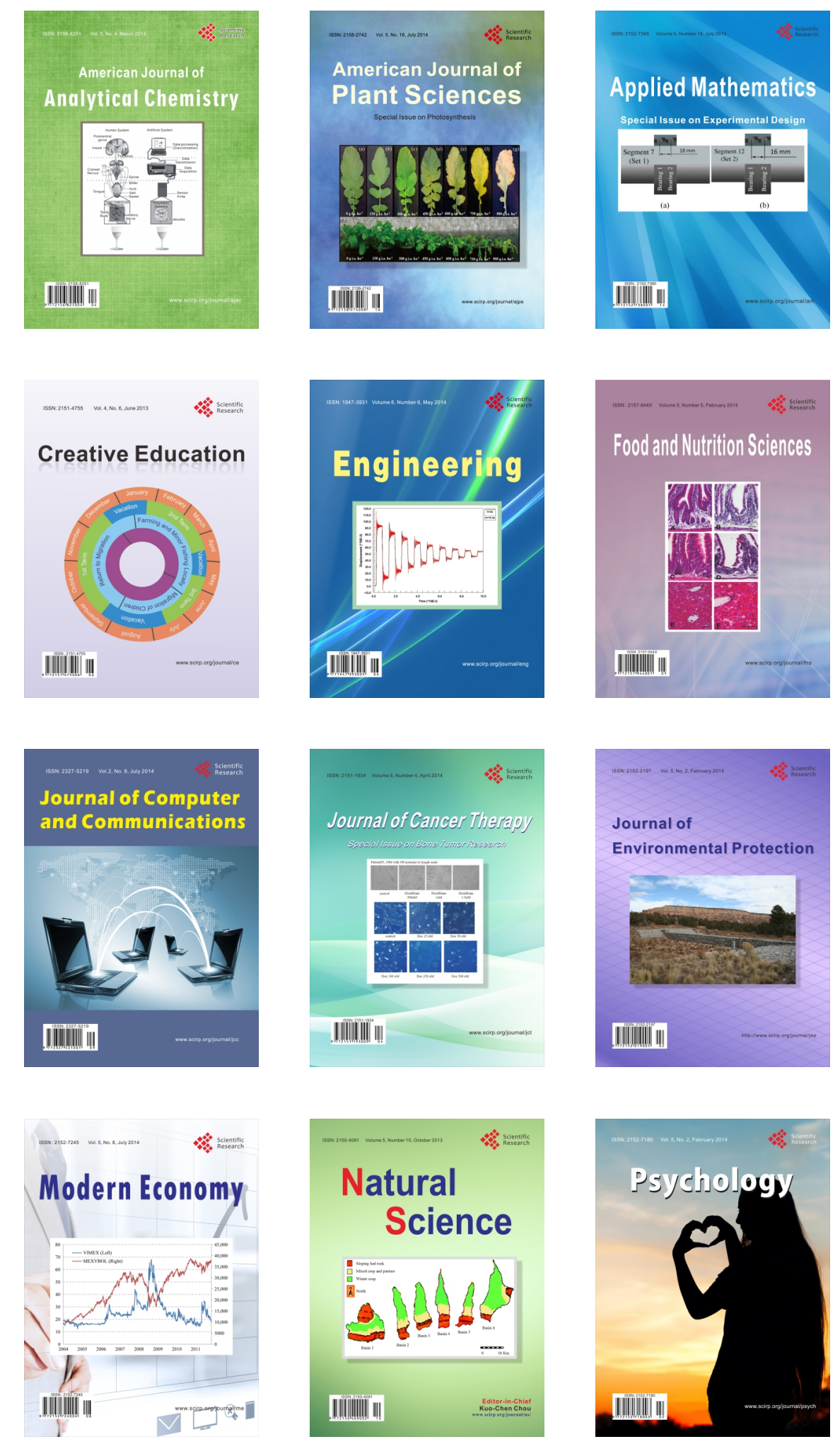